\title{
Blepharophimosis-intellectual disability syndrome, Verloes type
}

INSERM

\section{Source}

INSERM. (1999). Orphanet: an online rare disease and orphan drug data base.

Blepharophimosis-intellectual disability syndrome, Verloes type. ORPHA:293725

Blepharophimosis-intellectual disability syndrome, Verloes type is a rare, genetic multiple congenital anomalies/dysmorphic syndrome characterized by congenital microcephaly, severe epilepsy with hypsarrhythmia, adducted thumbs, abnormal genitalia, and normal thyroid function. Hypotonia, moderate to severe psychomotor delay, and characteristic facial dysmorphism (including round face with prominent cheeks, blepharophimosis, large, bulbous nose with wide alae nasi, posteriorly rotated ears with dysplastic conchae, narrow mouth, cleft palate, and mild microg nathia) are additional characteristic features. 